\title{
Narrativa radiofônica como estratégia para composição de audiolivros: uma proposta de classificação ${ }^{1}$
}

\author{
Debora Cristina LOPEZ ${ }^{2}$ \\ Andréa Franciéle WEBER ${ }^{3}$
}

\section{RESUMO}

Este artigo apresenta, a partir de uma aproximação a audiolivros, uma proposta de classificação em duas vias, sendo a primeira originária dos estudos de produção editorial, segundo o objetivo, e a segunda a partir da estrutura sonora. A primeira classificação é subdividida em: a) infantis; b) de ficção; c) de autoajuda; d) não ficção; e) científicos; e a segunda em: a) leitura simples; b) professoral; c) interpretação musicada; d) sonorização expressiva. Este texto traz resultados da primeira etapa de um projeto que pretende discutir estratégias sonoras, a partir da narrativa radiofônica, a serem utilizadas para construir audiolivros científicos voltados para um público específico: pessoas com deficiência visual parcial ou total. Um dos objetivos é, com o projeto, potencializar o processo de inclusão desses sujeitos e ampliar o acesso ao conhecimento científico.

Palavras-chave: Audiolivros, Inclusão, Narrativa Radiofônica, Classificação.

\begin{abstract}
This article presents an approach from the audiobooks, a proposal for classification in two ways, the first being the original studies of editorial production, according to the objective, and the second from the sound structure. The first classification is subdivided into: a) infant, b) fiction, c) self-help d) nonfiction e) scientific, and the second in a) simple reading b) professoral c) interpretation set to music d) expressive sound. This text presents the results of the first stage of a project that aims to discuss sonorous strategies, from the radiophonic narrative, to be used to build scientific audiobooks focused on a specific audience: people with partial or total visual disabilities. One of the goals of this project is to enhance the process of inclusion of these subjects and expand access to scientific knowledge.
\end{abstract}

Keywords: Audiobooks, Inclusion, Radiophonic narrative, Classification.

\footnotetext{
${ }^{1}$ Trabalho apresentado à quarta edição da Revista Ação Midiática - Estudos em Comunicação, Sociedade e Cultura, publicação ligada ao Programa de Pós-Graduação em Comunicação e Sociedade, da Universidade Federal do Paraná.

${ }^{2}$ Doutora em Comunicação e Cultura Contemporâneas pela Universidade Federal da Bahia. É professora do Programa de Pós-Graduação em Comunicação pela Universidade Federal de Santa Maria e da graduação em Jornalismo do campus Frederico Westphalen da mesma instituição. Coordena o Grupo de Pesquisa Convergência e Jornalismo (ConJor).

${ }^{3}$ Doutoranda em Letras-Estudos Linguísticos pela Universidade Federal de Santa Maria e professora do Departamento de Ciências da Comunicação do campus Frederico Westphalen da mesma instituição.
} 


\section{Proposta}

O audiolivro é conhecido no mercado editorial há anos. Como explicam Menezes e Franklin (2008), ainda na década de 1980, ele surgiu nos Estados Unidos e na década seguinte na Alemanha. Em ambos os países, foi integrado aos hábitos de leitura do público. No Brasil, surgiu antes, na década de 1970. A diferença principal entre os exemplos apresentados, destacam os autores, é que a produção brasileira restringia-se basicamente aos deficientes visuais. "Sua distribuição gratuita é realizada por instituições de caráter filantrópico, que produzem livros em Braille, livros falados e audiolivros com gravações de livros didáticos, periódicos e romances em diversos suportes [...]" (MENEZES; FRANKLIN, 2008, p. 62). Em 2011, segundo o Instituto Pró-Livro (apud PEREIRA, 2011), 2,9 milhões de brasileiros haviam aderido ao "livro falado", com uma média de 136 minutos de consumo semanal. À época, o instituto contabilizava 1.200 títulos no mercado, principalmente romances e livros técnicos (esses muito voltados para concursos públicos em áreas como o direito e a administração).

Mesmo após quase 40 anos presentes no país, os audiolivros carecem de pesquisas que auxiliem a compreensão de sua estrutura, dos seus potenciais narrativos e suas adequações ao contexto contemporâneo da convergência, no qual a miniaturização e o caráter multitarefa dos dispositivos móveis permitem o consumo em telefones celulares, players de mp3, smartphones, tablets, discmans e rádios de carro. Desta forma, acreditamos que, ao cruzar as áreas de narrativa e estética radiofônicas e os estudos sobre audiolivros, poderemos chegar a uma proposta de classificação que subsidie o desenvolvimento de protótipos, que serão testados e analisados através da realização de grupos focais com seu público potencial: pessoas com deficiência visual (total ou parcial).

Esta proposta integra o projeto de pesquisa "Formatos para áudio-livros científicos: inclusão social, experimentação e exploração dos potenciais da linguagem sonora em ambientes digitais", que surgiu da observação de uma lacuna nas produções de publicações científicas - especificamente no campo da Comunicação - neste formato, prejudicando sobremaneira o processo ensino-aprendizagem em cursos de graduação. Acreditamos que, através da produção sistemática de audiolivros científicos, 
seja possível trabalhar com bibliografias mais atualizadas, de maneira menos custosa e mais dinâmica, potencializando o processo de inserção do estudante com deficiência visual parcial ou total.

No projeto, que ainda se encontra em sua primeira etapa, pretendemos, através de três etapas de pesquisa, identificar e discutir usos e formatos para audiolivros em contexto de convergência. Este estudo parte das seguintes hipóteses: a) A narrativa e a estética radiofônica podem contribuir para a construção da narrativa de audiolivros, possibilitando uma conjugação de seu caráter expressivo e informativo; b) Os processos de convergência e de tecnologização levam a novos usos do audiolivro e demandam adaptações na sua estrutura narrativa e nas estratégias de diálogo que estabelece com seu público. Neste momento, ainda não conseguimos observar se essas hipóteses podem ou não ser comprovadas, mas já possuímos indicativos de que a tecnologização pode auxiliar na composição de uma narrativa mais atraente e de mais fácil compreensão para sujeitos com deficiência visual parcial, bem como de que a estética radiofônica não pode simplesmente ser replicada nos audiolivros, mas precisa ser adaptada às compreensões do sujeito deficiente visual, que tem no som seu referente central para a compreensão do conteúdo.

A pesquisa em questão se insere em um contexto complexo, que envolve inovações em práticas comunicacionais, criação, proposição de novos gêneros, além de um olhar mais flexível e inovador sobre as práticas e sobre o mercado editorial contemporâneo. Nos últimos anos, tem aumentado no Brasil a produção de audiolivros para um público sem deficiência, que o consome enquanto viaja ou no trânsito das grandes cidades. No entanto, essas obras têm, frequentemente, caráter ficcional ou de autoajuda. A proposta deste estudo é experimentar e discutir essa produção que tem se disseminado no mercado brasileiro, embora com entrada limitada no campo das obras científicas: o audiolivro. A partir de uma observação das produções de ficção e de autoajuda atuais, os procedimentos metodológicos preveem uma análise dos usos dos potenciais da narrativa radiofônica na composição de versões sonoras de livros científicos e didáticos direcionados, inicialmente, para pessoas com deficiência visual. Pensando em desenhar o contexto em que se insere esta proposta de pesquisa, a discussão teórica gira em torno de dois eixos: a narrativa radiofônica e a caracterização do audiolivro. 
Neste artigo apresentamos as primeiras aproximações com uma classificação de audiolivros ${ }^{4}$. Propomos duas linhas de classificação, a saber: 1) de acordo com os objetivos; 2) de acordo com a estrutura sonora. O primeiro deles divide-se em: a) infantis; b) de ficção; c) de autoajuda; d) não ficção; e) científicos. A segunda categoria pode ser dividida em: a) leitura simples; b) professoral; c) interpretação musicada; d) sonorização expressiva. Em ambas as classificações, consideramos o público alvo do projeto de pesquisa citado: pessoas com deficiência visual. Com base nesse objetivo, as classificações serão interpretadas, na discussão a seguir, a partir da perspectiva dos estudos sobre convergência e narrativa radiofônica.

\section{Discussão e análise}

A ampliação dos dispositivos multitarefa e multiplataforma no dia a dia da sociedade, como lembra Jenkins (2006), leva-nos a uma nova relação com os dispositivos e a uma modificação cultural. No contexto de convergência, um telefone celular, por exemplo, vai além do papel de comunicação básica e incorpora em suas funções a vez de reprodutor de áudio e vídeo, permite navegar pela internet, capturar imagens, áudios e vídeos, entre outras. Esta reconfiguração dos aparatos, que incorporam funções que originalmente não lhes diziam respeito, caracteriza o cenário da convergência e levam a novas formas de consumo de conteúdos, como é o caso do audiolivro. Para compreender essa nova relação, é preciso conhecer esse cenário.

Embora os debates sobre convergência tenham assumido maior visibilidade nos últimos anos, ele integra os estudos em comunicação há décadas. As primeiras tentativas de sistematização do conceito surgiram ainda na década de 70 , mais especificamente em 1978, com Negroponte e Pool no MIT. Neste momento, lembra Fidler (1998), a observação das mudanças que se estabeleciam no mercado de comunicação levou a uma tentativa de definição e organização da convergência como fenômeno acadêmico e comunicacional [Figura 01].

\footnotetext{
${ }^{4}$ Esta classificação parte de uma observação não sistematizada de audiolivros. Em um segundo momento da pesquisa, os produtos serão observados a partir da Análise de Conteúdo (BARDIN, 1988). Os resultados desta análise serão utilizados para produzir protótipos de audiolivros científicos em cada uma dessas categorias, que serão aplicados a um grupo focal de estudantes universitários com deficiência visual em distintos níveis.
} 
Figura 01: Convergência como fenômeno

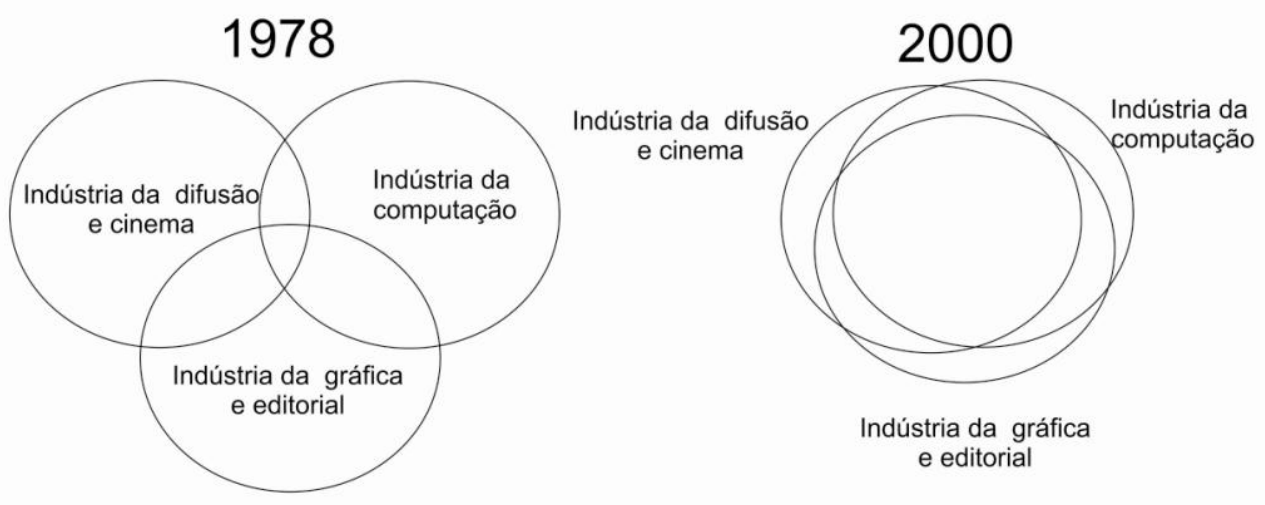

Fonte: FIDLER, 1998, p. 72.

Na década de 70, os pesquisadores observaram os indícios da aproximação entre as indústrias da difusão e cinema, da computação e gráfica editorial. Vinte anos depois, Fidler previu que nos anos 2000 esta fusão seria plena, e as três indústrias que ele considera cruciais para a comunicação e para a sociedade estariam em um processo de dependência e colaboração.

Essa expectativa, porém, não se concretizou e o conceito de convergência continua controverso apresentando pelo menos três grandes abordagens. Mas é fundamental, como indica Quinn (2005), chegar a um conceito comum, que permita o desenvolvimento do campo e a evolução dos meios e da sociedade. Trabalharemos aqui com duas escolas de estudos em convergência, que nos apresentam três perspectivas distintas: a escola americana e a escola espanhola. A primeira começa com os estudos de Negroponte nos anos 1970 e traz uma visão muito otimista do conceito e do fenômeno. A crítica central à abordagem destes pesquisadores reside no fato de serem essencialmente tecnológicos e, em grande medida, deterministas tecnológicos. Essa visão passa por uma relativização com a abordagem de Fidler, vinte anos depois, considerando a influência mútua entre os meios de comunicação - e não a influência da tecnologia - como uma via de mão única, como se fazia até então.

Ainda na escola americana é importante destacar o papel de Henry Jenkins (2006), que desloca o olhar tecnocêntrico do debate sobre a convergência, colocando como essencial o caráter cultural do fenômeno. Assim, o aumento da presença das 
$\overline{\text { tecnologias da informação e da comunicação ocorre na sociedade e não só nas empresas }}$ de comunicação. A presença de novos gadgets, o fortalecimento do uso das tecnologias, dos dispositivos multiplataforma e das novas formas de consumo e produção de informação têm, segundo o autor, uma consequência direta no cotidiano e não só na comunicação. Desta forma, novos hábitos diários, novas demandas levam à configuração de uma nova rotina profissional. Estas mudanças refletem-se, por exemplo, em uma alteração da relação que os sujeitos estabelecem com deadlines. A comunicação por email, o acompanhamento de processos judiciais através da internet, a utilização de home offices, a publicação de ebooks ou de livros em aplicativos para dispositivos móveis, entre outras tecnologias e processos, mudam a relação do sujeito consumidor com os produtos e produtores. Jenkins lembra que a convergência organiza conteúdos em distintos suportes, combinando diferentes mercados e adequando-se a um novo comportamento do público - agora menos fiel e mais variável. Para ele, o fenômeno da convergência deve ser observado sob duas perspectivas: a convergência dos meios de comunicação, a cultura participativa e a inteligência coletiva.

Os estudos de convergência dividem-se em três perspectivas: a) como inicial e tecnocêntrica que considera a tecnologia o único elemento determinante para as mudanças; b) como sistema, que considera a tecnologia um, mas não o único elemento gerador de mudanças na sociedade; c) como processo multidimensional, em que sujeitos, empresas e iniciativas de mudança encontram-se em estágios diversos e convivem entre si. Neste sentido, as questões regionais - que podem incluir especificidades da empresa, dos profissionais, dos consumidores ou das culturas locais são cruciais para a definição do caminho a seguir e das ferramentas a utilizar (QUINN, 2005). Para Salaverría e García Avilés (2008), trata-se de uma abordagem mais contextual que busca cruzar e relativizar os âmbitos que compõem esse processo. Desta forma, seriam consideradas as distintas gradações em que convivem as perspectivas de convergência empresarial, de conteúdo, profissional e editorial.

A convergência não diz respeito unicamente aos meios de comunicação. Ela relaciona-se com questões regionais que, como aponta Quinn (2005), variam de empresa para empresa, de país para país, enfim, que dizem respeito às culturas locais e aos sujeitos que compõem os espaços sociais. Esta perspectiva mais contextual, lembram Salaverría e García Avilés (2008), tem um caráter mais sistêmico, buscando 
indicar e analisar as esferas que integram este sistema. "Insistimos en que todos estos estudios, a pesar de concentrarse en aspectos concretos de la convergencia, parten de una concepción de la convergencia como un fenómeno orgánico, propiciado por la interrelación de diversos factores no exclusivamente tecnológicos" (SALAVERRÍA; GARCÍA AVILÉS, 2008, p. 34).

Trata-se de um contexto mais amplo, que envolve não só a comunicação, mas o ambiente em que ela se insere, as tecnologias presentes nele e os reflexos que elas têm nas ações e comportamentos do homem. "Na sociedade mecanizada são homens e mulheres que devem se adaptar ao ritmo e à aceleração das máquinas e não o contrário" (CUNHA, 2004, p. 15). Desta forma, os limites diluem-se tanto no uso das novas ferramentas no dia a dia quanto na sua utilização nas rotinas produtivas do jornalismo. Como explica Rojo Villada (2006), no passado, as ferramentas utilizadas em rádio, televisão ou impresso diferenciavam o trabalho dos jornalistas. Hoje, entretanto, ao trabalhar com o computador, que integra tecnologias de captação de informações, redação e edição, esta distinção está menos clara.

\section{Narrativa radiofônica}

Embora o rádio seja conhecido por sua característica monomídia, a cada dia sua interface com outras estratégias narrativas e a inserção da multimidialidade em suas rotinas têm levado o meio e os comunicadores que atuam nele a compreendê-lo de maneira diferente (LOPEZ, 2010). Entretanto, mesmo antes de inserir-se no contexto do rádio hipermidiático, a complexidade era parte da narrativa radiofônica. Comunicar através do som envolve compreender uma série de elementos que dialogam no processo de construção da informação e de transmissão de emoções e sensações. Como ressalta Balsebre, os sistemas expressivos que compõem a linguagem radiofônica são compostos por formas sonoras e não sonoras, pela música, pela palavra, pelo silêncio e pelos efeitos "cuya significación viene determinada por el conjunto de los recursos técnicoexpresivos de la reprodución sonora y el conjunto de factores que caracterizan el proceso de percepción sonora e imaginativo-visual de los radioyentes" (BALSEBRE, 2007, p. 27). 
Através da combinação destes elementos forma-se a mensagem e estabelece-se a comunicação, efetivando o processo de expressão do pensamento, envolvendo o ouvinte, fazendo com que ele seja transportado ao palco de ação, relacionando-se de maneira mais direta com o enredo apresentado, identificando-se com os personagens. Esta característica do rádio é potencializada no audiolivro, em que a atenção à informação é predominantemente concentrada (FERRARETTO, 2001), o que leva o ouvinte a sentir-se parte da história (como ocorre em audiolivros de ficção) ou da descoberta (no caso de audiolivros acadêmicos ou didáticos). Segundo Balsebre (2007, p. 117), "El efecto sonoro cumple así la función de factor de verosimilitud y ambientación objetiva, que impregna la configuración imaginativo-visual del radioyente de una sensación de realidad".

Através destes elementos é possível ambientar uma informação, explorando o som ou sua ausência como informação, contexto ou ilustração do conteúdo transmitido. O propósito é ativar e explorar a sensorialidade do ouvinte, característica do rádio, e aplicá-la a outras formas de comunicação, como as aplicadas ao mercado editorial. Em relação ao rádio, Martínez-Costa e Díez Unzueta (2005) defendem a especificidade dos gêneros e formatos aliados ao perfil de cada emissora e programa como definidores dos usos da linguagem radiofônica. Desta forma, conhecer o público para o qual se quer falar e o objetivo que tem a obra contribuem para a construção de uma narrativa sonora eficaz. Desta forma, os elementos utilizados nesta composição precisam ser sempre comuns a quem produz e a quem consome a informação.

A combinação entre esses elementos, no entanto, não é simples. As relações entre eles são complexas. A palavra, por exemplo, apresenta-se no texto, no tom, no ritmo, na clareza da locução, na maneira como dialoga com a trilha sonora e com os efeitos, nas inserções de silêncios e nas estratégias de edição. É uma narrativa complexa e intrincada que pode aproximar ou repelir o ouvinte, facilitar ou prejudicar a compreensão do que se pretende dizer e do tempo que se consegue manter o ouvinte conectado em uma determinada transmissão. Um dos propósitos é aproximar a locução e o contexto da fala de uma realidade dialogal. Para isso, lembra Prado (1989), além da reconstrução dos cenários, busca-se redesenhar a interlocução estabelecida entre os sujeitos no ar. "Deve-se desenvolver uma combinação de ritmos - mais rápidos e mais lentos - que reproduza as variações que se efetuam na expressão oral, em função da 
fluidez das idéias" (PRADO, 1989,p.24), reforçando o caráter conversacional e dialogal da fala e da narrativa oral.

\section{Audiolivro: usos da narrativa radiofônica em contexto de convergência}

O audiolivro, embora não seja uma novidade do contexto da convergência, tem recebido cada vez mais atenção de profissionais da área editorial e tecnológica. É possível dizer que sua origem reside no que Escolar Sobrino denomina de livro oral, anterior ao descobrimento da escrita. "[...] tomaron la forma de poemas, frases com medidas rítmicas, que podían llevar o no rima para recordarlos com facilidad y evitar que fueran inadvertidamente variados" (ESCOLAR SOBRINO, 2000, p. 09. Seu conteúdo era variado. Incluía desde leis e normas religiosas, poesia, mitos, códigos legais, todos organizados com sentenças breves e paralelismos para facilitar a memorização. Entre os exemplos mais famosos deste estilo estão poemas como Ilíada e Odisséia, de Homero, transcritos para o papel somente centenas de anos depois de sua criação. Esta estrutura simples com enredos completos pode ser observada hoje nos audiolivros - embora eles não dependam da memorização completa para sua retransmissão ou para sua compreensão.

$\mathrm{Na}$ área editorial, nos Estados Unidos, a produção e consumo de audiolivros é uma prática cristalizada. O mesmo ainda não ocorre no Brasil. Embora seu propósito central seja atender aos portadores de deficiência visual, Aquino (2008) lembra que, aos poucos, o consumo deste produto tem se disseminado, principalmente nas grandes cidades, onde o trânsito toma a cada dia mais horas do cidadão. Ou seja, o audiolivro vem despertando interesse dos consumidores e se firmando como um novo produto também no mercado editorial brasileiro.

Já do ponto de vista tecnológico, a disponibilização destas obras, lembram Bottentuit Jr et al (2009), tem sido afetada pelo avanço das tecnologias da informação e da comunicação. Costa et al (2004) explicam que a difusão através de extensões como wma, mp3, wave e rm facilitam a transmissão dos áudios por suportes digitais ampliando a abrangência da produção. "Segundo dados do IBGE, o Brasil possui 16,5 milhões de portadores de deficiência visual; destes, 5000 (33\%) possuem acesso ao computador e apenas 1000 à Internet". São dados preocupantes, mas é importante 
lembrar que o acesso à internet tem crescido exponencialmente no Brasil, assim como a difusão da banda larga. Por isso, é importante considerar a produção dos audiolivros no Brasil tanto sob uma perspectiva eminentemente sonora quanto sob a perspectiva multimídia, que inclua interfaces interativas para portadores de deficiência visual e para os demais consumidores (como games, diálogos com redes sociais, complementação de informações, fanfics, etc). Bottentuit $\mathrm{Jr}$ et al (2009) apontam para iniciativas interessantes de complementação de informações, como o "videoaudiolivro", que associa vídeos e áudios na construção de uma narrativa transmitida pela internet. Em ambos os casos, é preciso considerar a especificidade do público ao construir a narrativa sonora, ao treinar os "ledores" e pensar a edição do produto.

No contexto da web 2.0, o papel do leitor se altera, tornando-se mais interativo e mais ativo. Assim como a caracterização dos consumidores de informação (se é que se pode defini-los desta maneira) nativos digitais, agora o leitor é também produtor de conteúdo. Bottentuit Jr et al (2009) lembram que as ferramentas tecnológicas permitem hoje com facilidade ao leitor converter-se em autor, produzindo seus documentos e disponibilizando-os automaticamente através de sistemas simples, de interface amigável e, muitas vezes, gratuitos. Vale ressaltar, no entanto, que a autopublicação, quando não intermediada por sistemas como o Lulu.com, embora permita a divulgação da informação, não complementa o processo de editoração (ainda que de maneira mais simples), pois não conta com registros e/ou o aval de um conselho editorial. Assim, ainda que a produção de conteúdo esteja inserida em um contexto de convergência e de web social, a validação de um conselho editorial e o tratamento profissional dos originais por uma equipe editorial permitem não só o incremento da qualidade do trabalho, como a adequação dos originais ao público para o qual fala (tanto no que concerne ao texto quanto ao layout), como também a adequada distribuição da obra.

\section{Categorias propostas}

Compreender o papel e os potenciais dos audiolivros em um cenário de remediação (BOLTER; GRUSIN, 2000) requer compreender os pontos de contato entre as alterações nos dispositivos, em suas formas de fruição, nas possibilidades narrativas que oferece e nos objetivos que o produto apresenta. No caso específico do audiolivro 
voltado a um público com deficiência visual parcial ou total, é possível coordenar a narrativa sonora (seja ela simples, mais ilustrativa, ou imbricada, com perspectiva mais expressiva) e a multimídia, buscando elementos visuais que colaborem na transmissão da informação ${ }^{5}$.

Para sistematizar a observação a que nos propomos, buscamos adaptar para os audiolivros uma classificação oriunda dos estudos de produção editorial e da própria concepção de gênero midiático oriunda da indústria cultural. Assim, ao lançar um olhar sobre os produtos oferecidos no mercado, buscamos classificar audiolivros, a partir do seu objetivo, como: a) infantis; b) de ficção; c) de autoajuda; d) não ficção; e) científicos. Embora possa parecer simplesmente uma questão de divisão por conteúdo, a classificação por objetivos é determinante na seleção das estratégias sonoras a serem utilizadas.

A categoria infantil, por exemplo, prevê um processo imersivo, que se apropria de maneira mais intensa, o que Balsebre denomina caráter expressivo da linguagem radiofônica. Isso decorre das especificidades do público a que se dirige. As crianças pedem estímulos mais fortes e dinâmicos, que as motivem e conclamem a se envolver com o enredo e com os personagens da trama. Além disso, por contar uma história, normalmente composta por poucos personagens e enredo simples, as produções infantis permitem uma adaptação mais adequada às características de uma radiopeça (SPERBER, 1980), levando à exploração dos silêncios e sons em busca da composição de cenários sonoros e buscando propiciar uma experiência de consumo imersiva e envolvente.

No caso das obras de ficção, embora também contem uma história, podemos considerar que a estrutura básica de um romance permite a complexificação da história e a multiplicidade de personagens, o que o afasta da estrutura ideal para a composição de uma peça radiofônica, por essência mais simples e cotidiana. De acordo com a organização aristotélica (ARISTÓTELES, s/d), a narrativa tradicional apresentaria em sua organização algumas etapas: apresentação; complicação (que busca alterar a estabilidade dos personagens); clímax e desfecho (que permitiria a retomada de uma situação de equilíbrio decorrente de um conflito inicial). Essa complexificação vincula a

\footnotetext{
${ }^{5}$ Embora essa seja uma das proposições do projeto de pesquisa a que se vincula este artigo, nesse texto, centralizamos a abordagem na narrativa sonora para em uma etapa posterior coordenar essas categorias com as potencialidades dos dispositivos multimídia.
} 
produção de conteúdos de ficção, como acontece em outras categorias, à interpretação musicada, adaptação textual ou sonorização expressiva (esta em menor intensidade).

A categoria de autoajuda adota fundamentalmente a estrutura de leitura simples ou interpretação musicada. A estratégia central, para atingir o objetivo da obra, é apresentar argumentos simples - mais até do que os encontrados em radiopeças - e utilizar uma locução quase confessional. Essa locução retoma, em certa medida, uma característica da linguagem radiofônica, emulando uma conversa próxima e amiga, como se observa em programas de entretenimento e de aconselhamento.

Duas categorias dialogam em estrutura e conteúdo: a não ficção e a científica. Podemos incluir na não ficção produções como preparatórios para concursos públicos, predominantemente dos campos do direito e da administração de empresas. Neles, encontramos com maior frequência estruturas professorais, que simulam uma palestra ou uma aula, sendo frequentes estratégias como as repetições. Desta forma, o conteúdo é apresentado de maneira mais dialogal do que na leitura simples dos científicos e menos intimista do que nos audiolivros de autoajuda. Os científicos, como dito, adotam predominantemente a leitura simples e a adaptação textual. Isso se deve à complexidade dos argumentos e à necessidade de adaptar imagens, tabelas e gráficos ao formato, além da necessidade de reiterar e respeitar a noção de autoria dos conceitos.

Em relação à estrutura sonora, propomos uma organização em: a) leitura simples; b) professoral; c) interpretação musicada; d) sonorização expressiva; e) adaptação textual. Entre os audiolivros analisados, as categorias mais comuns eram a leitura simples e a sonorização expressiva. Trata-se dos dois extremos em relação à complexidade narrativa da proposta que trazemos, e essa presença justifica-se pela inserção dos infantis, de ficção e de autoajuda na amostragem ${ }^{6}$.

Os audiolivros de leitura simples não apresentam nenhuma alteração em relação ao livro impresso em estrutura ou adequação narrativa. Não explora trilhas, efeitos, silêncios expressivos ou variações de vozes para composição de personagens e/ou atribuição de ritmo. Em sua organização, somente uma voz lê (normalmente sem muita preocupação com interpretação ou entonações variadas) o conteúdo do livro sem realizar audiodescrição de imagens ou "reler" tabelas e gráficos. Trata-se do modelo mais simples e, por isso, muito comum em produções amadoras de livros científicos,

\footnotetext{
${ }^{6}$ Foram selecionados aleatoriamente dois audiolivros de cada categoria para essa aproximação.
} 


\section{REVISTA AÇÃOMIDIÁTICA - Estudos em Comunicação, Sociedade e Cultura}

Universidade Federal do Paraná

Programa de Pós Graduação em Comunicação

Vol 2. No 2. Ano 2012

quando se busca minimizar a ausência de obras adaptadas aos leitores com deficiência visual.

Uma estrutura semelhante apresenta a categoria professoral. Entretanto, com uma narração mais leve, já que se trata do áudio de aulas ou palestras - ou da simulação de uma aula ou palestra. Esta estrutura também não explora trilhas e efeitos, mas, por simular uma fala não lida, insere em seu repertório as entonações e os silêncios. Eles exercem um papel fundamental na caracterização da categoria, já que o tom professoral depende desses elementos para se estabelecer. Comum em audiolivros de não ficção, o tom professoral pode também ser adotado, em casos menos complexos, nos audiolivros científicos.

A interpretação musicada aparece com mais constância em obras de ficção. Em romances, por exemplo, a trilha sonora assume uma função ambiental, auxiliando na criação de sensações a serem transmitidas para o público. As músicas agem também como determinante do ritmo do audiolivro através de sua coordenação com silêncios e entonação. Nesta categoria, ao contrário da leitura simples, a interpretação do texto é fundamental e dialoga com o potencial narrativo dos demais elementos sonoros. Assim, aproxima-se de uma narrativa sonora mais complexa, embora ainda composta por argumentos e elementos mais simples em quantidade e articulação. Podemos identificar essa categoria em produções de autoajuda e ficção, mas observamos um potencial para sua exploração em audiolivros de não ficção e científicos.

A sonorização expressiva, assim como as categorias anteriores, não prevê alterações contundentes no texto original, mas adota ferramentas sonoras de composição da informação. Assim, através de som ambiente, efeitos, silêncios, música e entonação constrói uma narrativa complexa. Além da entonação, essa categoria explora a multiplicidade de vozes para compor a interpretação e permitir o estabelecimento do diálogo entre os personagens.

A adequação de textos aparece na última categoria, a adaptação textual. Ela inclui audiodescrição de imagens, além do detalhamento de fórmulas, esquemas, quadros, gráficos e tabelas. Também estabelece modos de organização sonora para elementos tipicamente presentes em obras escritas, como notas de rodapé, referências bibliográficas e todo tipo de remissão intratextual. Através da adaptação textual é possível utilizar a linguagem radiofônica, dialogal e de mais fácil compreensão sonora. 
Além disso, essa é uma categoria que pode ser combinada com outras de modo a melhorar a eficácia da transmissão do conteúdo.

\section{Considerações finais}

Este artigo traz resultados parciais da primeira etapa de uma pesquisa que busca compreender como as estratégias de narrativa radiofônica podem ser utilizadas para construir audiolivros científicos mais adequados a leitores com deficiência visual parcial ou total. Através deste estudo, buscamos ampliar o processo de inclusão dos portadores de necessidades visuais no processo de difusão do conhecimento científico, além de permitir o uso de dispositivos digitais móveis para potencializar a portabilidade, a circulação e o consumo deste conteúdo. Em um primeiro momento, tentamos identificar e discutir os possíveis usos e formatos para audiolivros em contexto de convergência para depois encaminhar essa discussão para as produções científicas. Partimos, para isso, da premissa de que os audiolivros têm potencial de atuar junto à inclusão e difusão de informações científicas.

Embora o audiolivro exista no Brasil há cerca de 40 anos, pouco se pesquisa sobre suas características e sobre seus potenciais narrativos. Fundamental para o processo de inclusão, através da minimização de dificuldades de portadores de necessidades no mundo da leitura, esta produção ainda é modesta no Brasil. Como dito, observa-se um crescimento nos investimentos em obras de ficção e autoajuda, mas muito pouca mudança no que diz respeito aos livros científicos e didáticos.

Segundo dados colhidos pelo IBGE em 2010, há no país mais de 6,5 milhões de pessoas com algum tipo de deficiência visual, sendo que, destas, quase 530 mil são cegas e pouco mais de seis milhões possuem baixa visão ou visão subnormal. Acreditamos que este público necessita de ações afirmativas que possam contribuir para sua plena inclusão no processo de educação formal e de construção do conhecimento científico, o que vai ao encontro das ações do Estado pela distribuição mais igualitária do direito ao ensino no Brasil.

Assim, audiolivros podem ser parte de um processo de inclusão de pessoas com necessidades visuais na construção do conhecimento característico do ensino superior ao facilitar a difusão das informações e do conteúdo específico das áreas. A proposta 
que apresentamos é coordenar, em produções sonoras classificadas como não ficção e científicas, elementos das categorias interpretação musicada, sonorização expressiva e adaptação textual. Desta maneira, acreditamos ser possível minimizar a poluição sonora existente na sonorização expressiva e, ainda assim, manter seus pontos positivos, permitindo a construção de um cenário sonoro e transmitindo emoções e sensações ao público.

Apresentamos essa proposta inicialmente porque acreditamos que a sonorização expressiva, embora seja adequada aos audiolivros infantis (que preveem envolvimento emocional entre história e leitor) prejudica a compreensão dos conceitos apresentados em obras científicas. Esse prejuízo é potencializado ao pensarmos em um público específico, os deficientes visuais que têm no som seu referencial principal, compreendendo os elementos sonoros de maneira distinta da audiência vidente. Para o público com necessidades visuais, o som assume um papel mais importante e potencializado - característica que deve ser considerada ao aliar uma abordagem expressiva suavizada com a adaptação de texto e a interpretação musicada.

\section{REFERÊNCIAS}

AQUINO, Sabine. No ar: o "livro falado". In: CONGRESSO BRASILEIRO DE CIÊNCIAS DA COMUNICAÇÃ̃o, 31., 2008, Natal. Anais...São Paulo: Intercom, 2008. CD-ROM.

ARISTÓTELES. Arte Poética. Trad. Paulo Costa Galvão. Rio de Janeiro: Ediouro, s/d. BALSEBRE, Armand. El Lenguaje radiofónico. 5a Ed. Madrid: Cátedra, 2007. BARDIN, Laurence. Análise de conteúdo. Lisboa: Edições 70, 1988.

BOLTER, Jay David; GRUSIN, Richard. Remediation: understanding news media. Cambridge: The MIT Press, 2000.

BOTTENTUIT JR, João Batista; LISBÔA, Eliana; COUTINHO, Clara. Livros digitais: novas oportunidades para educadores na era web 2.0. Atas da VI Conferência Internacional de TIC na Educação. Braga: Universidade do Minho, 2009.

COSTA, Valéria; CAMPOS, Marcus; SOARES, Karime. Da Celulose ao Som: o processo de gravação na Biblioteca Virtual Sonora. III Fórum de Informática Aplicada a Pessoas Portadoras de Necessidades Especiais - CBComp 2004. Disponível em: 
http://www.ufrgs.br/niee/eventos/CBCOMP/2004/html/pdf/Forum/t170100204_3.pdf. Acesso em: 10 jan 2013.

CUNHA, Mágda. O tempo do Radiojornalismo: a reflexão em um contexto digital. In: Estudos em Jornalismo e Mídia, Vol. I № 1 - $1^{\circ}$ Semestre de 2004.

ESCOLAR SOBRINO, Hipolito. Manual de la Historia del Libro. Madrid: Gredos, 2000.

FERRARETTO, Luiz Artur. Rádio: O veículo, a história e a técnica. $2^{\circ}$ ed. Porto Alegre, Sagra Luzzatto, 2001.

FIDLER, Roger. Midiamorfosis: Comprender los nuevos medios. Buenos Aires: Granica, 1998.

IBGE. Indicadores Sociais 2008. Pesquisa Nacional por amostragem domiciliar. Disponível em:

http://www.ibge.gov.br/home/estatistica/populacao/condicaodevida/indicadoresminimos /sinteseindicsociais2008/indic_sociais2008.pdf. Acesso em: 20 jan 2010.

JENKINS, Henry. Cultura da Convergência. São Paulo: Aleph, 2006.

LOPEZ, Debora Cristina. Radiojornalismo hipermidiático: tendências e perspectivas do jornalismo de rádio all news brasileiro em um contexto de convergência tecnológica. Covilhã: LabCom Books, 2010.

MARTÍNEZ-COSTA, Maria Del Pilar; DÍEZ UNZUETA, José Ramón. Lenguaje, géneros y programas de radio: introducción a la narrativa radiofónica. Pamplona: EUNSA, 2005.

MENEZES, Nelijane; FRANKLIN, Sérgio. Audiolivro: uma importante contribuição tecnológica para os deficientes visuais. PontodeAcesso, Salvador, v. 2, n. 3, p. 58-72, dez. 2008.

PEREIRA, Robson. Livro falado conquista espaço no mercado jurídico. Consultor Jurídico. 2011. Disponível em: http://www.conjur.com.br/2011-abr-15/audiolivrosconcursos-avancam-mercado-juridico. Acesso em: 19 mar. 2013.

PRADO, Emilio. Estrutura da Informação Radiofônica. São Paulo: Summus, 1989. QUINN, Stephen. Convergent Journalism: the Fundamentals of multimedia reporting. New York: Peter Lang Publishing, 2005.

ROJO VILLADA, Pedro Antonio. Prensa y convergencia tecnológica: Claves para la definición de un nuevo modelo de negocio periodístico en la Era Digital. Zer, 20, 2006, p. 411-424. 
SALAVERRÍA, Ramón; GARCÍA AVILÉS, José Alberto. La convergência tecnológica en los medios de comunicación: retos para el periodismo. Trípodos, número 23, Barcelona, 2008.

SPERBER, George Bernard (org). Introdução à Peça Radiofônica. São Paulo: EPU, 1980. 